\title{
Configurações
}

Revista de sociologia

$10 \mid 2012$

Políticas Públicas

\section{Entre a produção habitacional estatal e as moradias precárias: uma análise da popularização da casa própria no Brasil}

Between the state production and the poor housing: an analysis of the popularization of private housing in Brazil

Entre les logements sociaux de l'État et le logement précaire : une analyse de la vulgarisation des logements privés au Brésil

\section{Walkiria Zambrzycki Dutra}

\section{OpenEdition}

\section{Edição electrónica}

URL: http://journals.openedition.org/configuracoes/1487

DOI: $10.4000 /$ configuracoes. 1487

ISSN: 2182-7419

\section{Editora}

Centro de Investigação em Ciências Sociais

\section{Edição impressa}

Data de publição: 1 Dezembro 2012

Paginação: 151-164

ISBN: 1646-5075

ISSN: 1646-5075

\section{Refêrencia eletrónica}

Walkiria Zambrzycki Dutra, « Entre a produção habitacional estatal e as moradias precárias: uma análise da popularização da casa própria no Brasil », Configurações [Online], 10 | 2012, posto online no dia 17 fevereiro 2014, consultado o 19 abril 2019. URL : http://journals.openedition.org/ configuracoes/1487; DOI : 10.4000/configuracoes.1487 


\title{
Entre a produção habitacional estatal e as moradias precárias: uma análise da popularização da casa própria no Brasil
}

\author{
Between the state production and the poor housing: an analysis of the \\ popularization of private housing in Brazil \\ Entre les logements sociaux de l'État et le logement précaire : une analyse de la \\ vulgarisation des logements privés au Brésil
}

Walkiria Zambrzycki Dutra

\section{Introdução}

1 As cidades têm proporcionado o espaço físico e ideológico para a construção das interações econômicas, políticas e sociais em todo o mundo ao longo do século XX. Para qualquer uma dessas esferas, a distribuição da riqueza produzida é visivelmente díspar ao levar em conta, por exemplo, as diversas formas encontradas pelos indivíduos para a moradia.

2 Em países em desenvolvimento como o Brasil, o aumento expressivo no número de favelas e moradias precárias nos principais centros urbanos reflete a única alternativa disponível para grande parte da população de baixa renda: a autoconstrução (Bonduki, 1994; Maricato, 2011; Souza e Carneiro, 2007).

O passivo coletivo gerado caminha para a segregação territorial e social da cidade em centro-periferia, constituindo verdadeiras "bombas socioecológicas" (Maricato, 2011:8). ${ }^{1}$

4 Tomando como estudo de caso o Brasil, este artigo busca discutir a resposta do poder público para solucionar o problema do acesso à moradia para as famílias de baixa renda. Para tanto, em primeiro lugar, discute-se o papel do Estado vis-a-vis a lógica de mercado 
na provisão de políticas de bem-estar social, em especial a habitação. Para os países de industrialização tardia, houve dificuldades na consolidação de uma política abrangente a todos os indivíduos da sociedade, uma vez que se restringia esse direito à classe formalmente empregada.

$\mathrm{Na}$ segunda parte do artigo, analisa-se mais especificamente a promoção da política habitacional, enquanto política de bem-estar social nos dois períodos de maior institucionalização e registro de unidades habitacionais construídas. O primeiro compreende o Regime Militar (1964-1985), cujo aparato institucional tinha o setor privado como principal parceiro do governo nesta política. O segundo momento corresponde ao período atual (2003-2012), em que se mantém a parceria entre o setor público com o privado, mas se desarticula a casa própria do espaço urbano.

Questionamos na terceira parte do artigo a real função da política habitacional, enquanto provedora de bem-estar social. Dada a especificidade do bem provido (a casa própria) e a intrínseca relação desenvolvida entre o setor público e o setor privado ao longo das décadas, a moradia se aproxima, na maior parte dos casos, de uma solução econômica e não necessariamente de desenvolvimento social.

\section{A Seguridade Social, as Políticas Sociais e o Papel do Estado}

7 A organização do espaço urbano tem sido área de interesse dos estudos que tratam do acesso à terra, da moradia, da mobilidade, da infraestrutura, da participação social e até mesmo da consolidação das metrópoles enquanto organização política autônoma (Lefèvre, 2009; Maricato, 2011). Todas essas questões afloram com o desenvolvimento das atividades industriais, do comércio e, mais recentemente, dos serviços, que acumulam riquezas e condicionam as relações sociais e de trabalho nas cidades.

8 A aplicação do pensamento liberal considera que há um funcionamento perfeito na distribuição desta riqueza a partir da relação de troca entre os que ofertam o capital e os que ofertam o trabalho (Höfl ing, 2001). Mas com a primeira grande crise econômica mundial na década de 1930, a intervenção do Estado na economia é discutida em duas frentes: enquanto regulador das ações de troca no mercado; e como ator que busca diminuir as desigualdades estruturais produzidas pelo crescimento socioeconômico.

Os países precursores desse debate são as economias avançadas (principalmente os da Europa Ocidental) que, com o término da Segunda Guerra Mundial, em 1945, iniciam um processo de "reconstrução econômica, moral e política" (Esping-Andersen, 1995:73) conhecido como welfare state (em português, estado de bem-estar social). Segundo o autor, abandonam-se as ideias liberais anteriores a favor de uma visão de ganhos para a cidadania, justiça social, solidariedade e universalismo. A partir de então, está-se argumentando a favor de políticas sociais que harmonizem o modo de produção capitalista com as condições de vida do principal participante desta estrutura: o trabalhador (Gomes, 2006).

O direito à educação, ao trabalho, à saúde, à aposentadoria e demais serviços necessários ao bem-estar do cidadão compõem os chamados direitos sociais (Carvalho, 2011). A maneira pela qual o Estado interfere para a garantia destes é o que chamamos de política social (Höfling, 2001). Tal estratégia em direção ao investimento em capital humano tem 
tanto o objetivo de evitar pressões sociais, bem como promover projetos nacionais de desenvolvimento econômico (Esping-Andersen, 1995; Gomes, 2006).

11 Este novo esteio ideológico não se consolidou de maneira uniforme entre os países que tentaram implementá-lo. Diferentes conceções de como coletivizar a assistência aos indivíduos pode ser pensada a partir de um contínuo; num extremo, tem-se numa versão tímida de bens e serviços a partir do mínimo necessário para a regulação e manutenção da ordem social; no outro extremo, parte-se para a total cobertura de proteção social nas situações de marginalidade e pobreza (Souza e Carneiro, 2007).

12 Este artigo chama atenção para algumas considerações a respeito dessa discussão. Em primeiro lugar, é necessário ter em mente que a natureza da política social é fator fundamental para se caracterizar a interferência do Estado, enquanto promotor de políticas de bem-estar social. Há diferentes tipos de bens e serviços a ser oferecido aos cidadãos, no sentido de torná-los de uso coletivo ou privado, de atendimento universal ou focado a certas faixas de renda. O principal determinante para tal é a relação entre os grupos de interesse que se posicionam, enquanto setor público e setor privado.

13 A partir do estudo de caso das políticas urbanas, mais especificamente a habitacional, é possível ter distintas formas de articulação entre o Estado e os agentes privados ligados à construção civil, bancos e as sociedades de crédito imobiliário. Isso ocorre devido às diversas etapas que compõem a natureza desse setor, a saber: a captação do investimento; a produção da unidade habitacional; o financiamento da mesma; a sua comercialização; e o consumo via beneficiário final (o cidadão) (Arretche, 1990).

O segundo ponto dinamizador de debates na provisão de políticas sociais e de bem-estar social é a interferência do Estado. Na área de habitação, há dois modelos paradigmáticos implementados durante o welfare state: o caso sueco e o caso norte-americano. Em relação ao modelo do país escandinavo, o Estado considerou que o direito à moradia era direito de todos os cidadãos. Para isso, era necessário que este atuasse de forma a reduzir o impacto da renda, o que foi atingido em duas etapas do processo. No que se refere à produção de unidades habitacionais, foram realizados contratos diretamente com agências estatais para a construção dessas novas unidades (Arretche, 1990).

15 Em relação à promoção imobiliária, as agências públicas, sociedades habitacionais sem fins lucrativos, e cooperativas habitacionais assumiram diretamente esta tarefa. Os dois fatores estratégicos para garantir que não houvesse "boicote" por parte dos promotores privados foram: a) a garantia do acesso ao financiamento via regulação pública do mercado imobiliário; e b) a garantia da terra urbana disponível mediante desapropriação (Arretche, 1990).

o caso norte-americano é caracterizado como um modelo liberal, pois a intervenção do Estado se limitou a ações regulatórias via estruturação do modo de operação do sistema habitacional, mas sem a interferência direta do Estado nas relações de compra, venda ou financiamento (Arretche, 1990). Assim, as condições para o financiamento habitacional ocorreram via associações de poupança e empréstimo privadas. A política social de habitação, no sentido de provisão para as famílias consideradas de mais baixa renda, atuou principalmente através de subsídios para a produção das unidades habitacionais produzidas pelo setor privado, de forma a estimular a participação deste setor (Arretche, 1990).

Na relação entre o setor público e privado nas políticas sociais, ao considerar a América Latina e, mais especificamente, o Brasil, muitos autores argumentam que não houve a 
consolidação de um sistema de bem-estar social, a não ser por ações pontuadas em algumas áreas e para alguns setores da sociedade (Esping-Andersen, 1995; Gomes, 2006; Mello, 2007). Tal ação decorre dos mecanismos institucionais de cunho protecionista denominado "Estado empreendedor" devido à sua interferência direta para a promoção do bem-estar social e desenvolvimento econômico (Esping-Andersen, 1995).

No Brasil, o controle do Estado nos meios de produção e nas relações de trabalho possibilitou a promoção de políticas sociais que aliavam os interesses nacionais e da classe empresária emergente (Gomes, 2006). O principal resultado tem sido a submissão dos direitos sociais à lógica da produção, em que a busca pelo crescimento econômico não se compatibiliza com o processo de desenvolvimento social, pensamento inverso aos países precursores do welfare state.

Outro problema para a realização da lógica do "Estado empreendedor" está no financiamento das políticas sociais. No caso da habitação, entre as décadas de 1930 a até aproximadamente o fi nal dos anos 80 , utilizaram-se fundos de contribuição compulsória dos trabalhadores urbanos formalmente empregados na economia. ${ }^{2}$ Tal opção restringe o investimento a outras parcelas da sociedade - em destaque para os desempregados e trabalhadores informais - que acabam por suprir o acesso à moradia segundo a provisão informal e ilegal (Bonduki, 1994; Souza e Carneiro, 2007).

Esta alternativa, conhecida como da autoconstrução, significa dizer que na maior parte dos casos a informalidade reflete condições sanitárias insuficientes, falta de luz e até mesmo ausência de ventilação no espaço domiciliar, um local no geral propício para o surgimento de várias doenças (Bonduki, 1994). A ilegalidade se refere à posse ilegal do terreno onde se deu a autoconstrução. Este é cenário perseguido desde o crescimento dos grandes centros urbanos, como veremos a seguir.

\section{A Provisão da Política Habitacional}

21 Desde 1891, o Brasil organiza-se como uma república de regime presidencialista e federalista. 0 princípio federativo atribui uma divisão das atividades do governo entre um poder central e um poder subnacional (ou constituinte), em que cada um deles possui autonomia para tomar a decisão final sobre, no mínimo, alguma atividade específica (Riker, 1975). De 1891 a 1987, o país possui um Governo Federal e os Governos Estaduais como as unidades subnacionais. A partir da promulgação da Constituição Federal de 1988, mantêm-se os governos estaduais e cria-se um novo ente federado, o município.

22 No entanto, entre os anos de 1964 a 1985, o federalismo brasileiro foi interrompido pelo golpe militar que anulou na prática a autonomia dos governos estaduais, enquanto entes federados, além de restringir os direitos políticos dos cidadãos. Assim, toda a formulação e planejamento de políticas e diretrizes se davam no Governo Federal, caracterizando uma gestão altamente centralizadora e não participativa.

23 O Regime Militar é também um momento importante para a industrialização brasileira, pois as taxas de crescimento econômico alcançam valores próximos a 10\% ao ano (Mello, 2007). 0 aumento na produção industrial vivenciada em proporção nunca antes vista no país atrai grande fluxo migratório da população para as cidades, como aconteceu com S. Paulo no final do século $\mathrm{XIX}^{3}$, nos primórdios do êxodo rural para as grandes cidades.

24 A ausência de oferta de moradias associada aos baixos salários e desemprego de grande parte dos novos habitantes impede-os de estabelecer moradia via aluguer ou 
financiamento do imóvel residencial. A opção disponível consiste nas habitações precárias, cujo aglomerado viria a chamar-se favelas (Maricato, 2011).

As tentativas anteriores de intervenção habitacional atuaram de forma ineficiente devido principalmente à fonte de recurso disponível. Ainda, a ausência de regulação do setor imobiliário de alugueres dificultava o acesso das famílias de mais baixa renda, fatores que justificam o déficit habitacional de aproximadamente oito milhões de unidades habitacionais no início dos anos 60 (Santos, 1999). ${ }^{4}$

Como resultado, o governo entende que esta é uma área prioritária de investimento social. Um dos principais desafios era saber como atuar, considerando os problemas já verificados nas décadas anteriores e que permaneciam sem solução, a saber: a concentração do problema nas famílias com até três salários mínimos; o difícil acesso dessa parcela da população à terra urbanizada; e o difícil acesso dessas famílias ao mercado imobiliário de aluguéis devido ao baixo poder aquisitivo e capacidade de financiamento (Santos, 1999).

A casa própria tem sido a conceção de atendimento do poder público na área habitacional pela imagem por ela representada: um bem de alto valor agregado que traz status social ao trabalhador (Bonduki, 1994; Vitruvius). 0 governo militar dá suporte a essa ideia, pois se acreditava também que através da promoção de políticas conservadoras (como o direito à propriedade) ter-se-ia apoio popular ao regime (Gomes, 2006; Mello, 2007).

Assim, buscou-se criar um aparato financeiro e institucional robusto, um sistema que possibilitasse o acesso à casa própria através do crédito habitacional (Arretche, 1990). No desenho institucional proposto, o setor público atuaria como agente financiador e gestor dos recursos através de uma fonte voltada exclusivamente para a política urbana. Este ator também atuaria como planejador do tipo de construção a ser empreendida, apelidada de "casa popular". Coube ao setor privado a construção propriamente dita das unidades habitacionais, bem como a comercialização destas ao consumidor final.

29 A necessidade de criação de um aparato financeiro para a habitação se justifica pela forma de atendimento desta política pelo governo: financiar a casa própria sem dar subsídios, com baixas taxas de juros e período de pagamento estendido em mais de 10 anos (Santos, 1999). Visando este fim, em 1966 foi criado o Sistema Financeiro de Habitação (SFH), que agia como uma captação de poupança de longo prazo voltado para os investimentos em habitação (Santos, 1999). As suas principais fontes de recurso eram o Sistema Brasileiro de Poupança e Empréstimos (SBPE) - um sistema de poupança voluntário e privado - e o Fundo de Garantia por Tempo de Serviço (FGTS), este recém-criado pelo governo e que tinha como fonte de receita "as contribuições compulsórias dos trabalhadores empregados no setor formal da economia” (Santos, 1999:10).

Com o SFH esperava-se criar uma fonte de financiamento que fosse estável, de longo prazo e autofinanciada. A estrutura institucional responsável tanto pelo gerenciamento, normatização e fiscalização dos recursos do FGTS e das cadernetas de poupança do SBPE, bem como pela coordenação das atividades habitacionais era o Banco Nacional de Habitação (BNH), órgão ligado ao Governo Federal (Santos, 1999).

31 Com a estrutura do SFH define-se a atuação dos agentes privados e públicos da seguinte forma. Os recursos do SBPE se voltam para o investimento habitacional de famílias de classe média e alta (acima de cinco salários mínimos) propostos por empreendedores ou construtoras privadas que também se responsabilizavam pela venda dessas unidades (Santos, 1999). Os recursos do FGTS atenderiam às famílias de mais baixa renda, cujos 
principais agentes promotores seriam as Companhias de Habitação (COHAB): agências estatais associadas a empresas privadas de construção civil (Arretche, 1990; Santos, 1999).

Neste caso, o setor público acaba por substituir o setor privado e passa a atuar como um ator privado: obtinha financiamento junto ao $\mathrm{BNH}$; produzia as unidades habitacionais segundo o projeto arquitetônico estipulado pelo BNH - e conhecido como "casas populares" (Bonduki, 1994); supervisionava a construção das mesmas - via contratos de licitação; e se responsabilizava pela venda da unidade habitacional às famílias de baixa renda (Santos, 1999).

O funcionamento da política habitacional aos moldes do BNH esteve em vigência até a metade da década de 1980, quando o país enfrenta uma grave crise financeira que atingiu tanto a fonte de financiamento do $\mathrm{BNH}$, quanto a capacidade de pagamento dos mutuários - principalmente os de mais baixa renda. Como consequência, tem-se o fechamento do BNH seguido de um período de crise financeira e institucional neste setor até ao início dos anos 2000 (Klintowitz, 2011; Valença, 1999).

Ao longo da década de 1990, é extensa a literatura que analisa os resultados qualitativos e quantitativos atingidos pela política do BNH-SFH (Arretche, 1990; Bonduki, 2007; Cardoso, s/d; Maricato, 1987; Santos, 1999; Valença, 1999). Em números, a tabela 1 abaixo compilada no estudo de Melo apud Arretche (1999) nos permite aferir que o SFH fi nanciou cerca de 4 milhões de novas unidades habitacionais, seja via SBPE ou COHABs. Este valor corresponde a 25\% das novas moradias construídas no país entre 1964 a 1986, valor que, embora insuficiente para solucionar a questão do déficit habitacional, é considerado tanto de relativa importância (Arretche, 1990; Bonduki, 2007) quanto de críticas (Cardoso, s.d).

QUADRO 1 - NÍVEL DE INTERMEDIAÇÃO fINANCEIRA NA CONSTRUÇÃO HABITACIONAL NO BRASIL (1964-1986)

\begin{tabular}{|c|c|c|c|}
\hline \multirow{3}{*}{ Anos } & \multirow{3}{*}{$\begin{array}{l}\text { Novas unidades habitacionais } \\
\text { construídas\% (em milhões) } \\
\text { (a) })^{1}\end{array}$} & \multicolumn{2}{|c|}{ Novas unidades financiadas pelo SFH } \\
\hline & & (em milhões) & (em \%) \\
\hline & & $(b)^{2}$ & $\mathrm{a} / \mathrm{b}$ \\
\hline $1964-70$ & $2,3 * *$ & 0,5 & 17,4 \\
\hline $1971-78$ & 5,6 & 1,5 & 26,8 \\
\hline $1979-80$ & 2,3 & 1,1 & 47,8 \\
\hline $1979-83$ & 5,1 & 2,1 & 41,1 \\
\hline $1984-86$ & 2,5 & 0,2 & 8,0 \\
\hline Total 1964-86 & 15,5 & 4,8 & 25,8 \\
\hline
\end{tabular}

FONTE: ELABORADO POR MELO APUD ARRETCHE (1990:28). (1) FONTE: PNADS 1978, 1983, 1986, CENSOS 1960, 1970, 1980. (2) FONTE: HABITAÇÃo E POUPANÇA, 1988, MAIO, P. 16. * TOdos OS TIPOS DE HABITAÇÃO (INCLUSIVE BARRACOS, ETC) ** ESTIMADO POR INTERPOLAÇÃo

35 A produção habitacional acima visualizada coincide com a trajetória das COHABs e da capacidade de financiamento do SFH. Segundo Maricato (1987), entre 1964 a 1969 houve o processo de implantação e expansão do financiamento e construção para as famílias de baixa renda. Entre 1970 a 1974 houve ligeiro esvaziamento e crise devido à inadimplência e baixo retorno do investimento a este setor. A partir de 1975 até os anos 80 as COHAB's passam a construir unidades habitacionais para as faixas de renda superior, em busca de 
clientes que gerasse lucro para essas empresas. A partir de 1982, a estrutura do BNH entra em crise, e com ela a produção habitacional via SFH.

A lógica de acumulação privada esteve associada ao poder público enquanto função de produção e comercialização habitacional volta-se para o lucro, o que indica que o retorno da política habitacional em termos econômicos é melhor do que perseguir uma política social voltada para os que mais necessitam do Estado. Como resultado, a tabela 1 também nos permite visualizar o aumento do número de unidades habitacionais construídas fora do sistema SFH, o que significa dizer expansão de favelas e marginalização social (Arretche, 1990).

Com o fim da primeira política nacional de habitação, a década de 1990 preconiza o reajuste fiscal e econômico do país via reforma do Estado e grande participação do setor privado na provisão das políticas sociais (Valença, 2001).

A nova política nacional de habitação terá início em 2003 com a gestão de Luís Inácio Lula da Silva, e ainda se encontra em implementação nos dias atuais. ${ }^{5}$

A principal diferença no desenho institucional proposto é diferenciar o déficit habitacional da inadequação de moradias. $O$ primeiro termo concentra medidas voltadas para sanar o número quantitativo de novas unidades habitacionais a serem produzidas. 0 segundo termo entende que é necessário requalificar as unidades habitacionais existentes através de melhores condições de infraestrutura (Fundação João Pinheiro, 2009).

A partir do recém-criado Ministério das Cidades (MCid), em 2003, a Nova Política Nacional de Habitação (PNH) criada em 2004 traz quatro eixos de atuação do MCid, a saber:

Modelo de financiamento e subsídios [para a produção de unidades habitacionais]; política urbana e fundiária [políticas voltadas para a gestão e uso do solo]; desenho institucional [ligado à capacitação institucional de Governos Estaduais e municípios]; e cadeia produtiva da construção civil voltada à habitação de interesse social (Brasil, 2009: 13).

41 Essas demandas eram almejadas por vários analistas do setor, no sentido

de interpretar a questão habitacional como uma questão mais ampla em termos 2012). Busca-se, neste primeiro momento, ampliar o atendimento público habitacional a outras necessidades conjugadas à casa própria.

No entanto, a estrutura financeira voltada para a política habitacional ainda é composta por praticamente os mesmos atores do período militar. O SFH continua em funcionamento até ao presente momento, apesar de ter sofrido reestruturação na década de 90 (Valença, 2001). As COHABs continuam atuando como agências estatais na produção de unidades habitacionais, e o extinto BNH é realocado para Caixa Econômica Federal (CEF), banco público também controlado pelo Governo Federal.

Em 2008, uma nova crise econômica mundial iniciada pelo setor imobiliário norteamericano afeta os mercados financeiros que, ao chegar ao Brasil, gerou "incertezas e uma paralisia no setor [habitacional], pego no contrafluxo, pois estava em pleno processo de aceleração da produção" (Bonduki, 2009:11).

Uma das alternativas encontradas pelo governo brasileiro para contorná-la foi incentivar o mercado interno através da construção civil com a criação do programa federal Minha Casa, Minha Vida (MCMV), em 2009. O objetivo é estimular a produção e a aquisição de novas unidades habitacionais através da concessão de subsídios ao financiamento da 
unidade habitacional, distribuídos segundo faixas de renda. As metas do programa podem ser mais bem visualizadas na tabela 2, exposta a seguir.

QUADRO 2 - DÉficIt ACUMULADO E AS METAS dO PROgRAMA MINHA CASA, MINHA VIDA DISTRIBUIÇÃo do dÉficIT POR FAIXA DE RENDA (2009)

\begin{tabular}{cccccc}
\hline \multirow{2}{*}{$\begin{array}{c}\text { Renda } \\
\text { (em RS) }\end{array}$} & Déficit acumulado & Metas do MCMV & $\begin{array}{c}\text { Déficit } \\
\text { acumulado } \\
\text { atendido }\end{array}$ \\
\cline { 2 - 6 } & (em \%) & $\begin{array}{c}\text { (valor } \\
\text { absoluto, } \\
\text { em mil) }\end{array}$ & (em \%) & $\begin{array}{c}\text { (valor } \\
\text { absoluto, } \\
\text { em mil) }\end{array}$ & (em \%) \\
\hline Até 1.395 & 91 & 6.550 & 40 & 400 & 6 \\
\hline 1.395 a 2.790 & 6 & 430 & 40 & 400 & 93 \\
\hline 2.790 a 4.600 & 3 & 210 & 20 & 200 & 95 \\
\hline Total & 100 & 7.200 & 100 & 1.000 & 14 \\
\hline
\end{tabular}

FONTE: ELABORADO POR BONDUKI (2009:13), A PARTIR DE DADOS DISPONÍVEL PELA FUNDAÇÃo JOÃo PINHEIRO E PELO fOlHeto de divUlgaçÃo do PROgRAMA MiNHA CASA, MiNHA VIDA (MCMV).

Segundo a tabela 2 - elaborada por Bonduki (2009) a partir de dados fornecidos pela Fundação João Pinheiro e o programa MCMV - o principal objetivo do programa MCMV é produzir 1 milhão de novas unidades habitacionais. Como é de se esperar, a meta de construção está concentrada no estrato de maior déficit habitacional: as famílias de até três salários mínimos (que à época da elaboração da tabela correspondia a R\$1395,00), correspondendo a $91 \%$. O segundo maior estrato a ser atendido são as famílias compreendidas entre a renda familiar mensal de três a seis salários mínimos.

O primeiro grande incentivo do programa está voltado para a produção via setor privado, com a contratação de empreiteiras e construtoras que apresentam os projetos à CEF (Vitruvius). O segundo incentivo dessa política é a aquisição via subsídio total para as famílias de mais baixa renda (com maior concentração de déficit habitacional), e subsídio parcial para as famílias entre três a seis salários mínimos (Bonduki, 2009). A fonte de recursos para os subsídios permanece sendo via FGTS, e a principal estratégia do governo continua sendo via casa própria.

Assim, é possível perceber que se mantém a lógica de financiamento da casa própria via recursos federais, com o setor privado responsável pela produção. As consequências dessas medidas serão discutidas a seguir.

\section{A articulação da economia e do bem-estar social sob a ótica da moradia}

51 Tendo em vista o processo de provisão da casa própria como política social prioritária na área de habitação, o desenho institucional proposto tanto no regime militar (1964-1985) quanto no período atual (2003-2013) encontram dificuldades em atender às classes de renda mais baixa sem reduzir o lucro em termos financeiros do setor da construção civil.

Em primeiro lugar, vale mencionar a opção do poder público em participar ativamente de praticamente todas as etapas do processo produtivo do setor habitacional (Arretche, 
1990). Na função de agente regulador, há forte presença nas operações de fluxo de crédito e transações para o setor da construção civil, além da regulamentação do crédito destinado ao consumidor final para os recursos do SBPE. No entanto, há quase total ausência regulatória no tipo de unidade habitacional a ser produzida: "sequer para tetos/ tabelamentos dos preços das mercadorias e seus componentes, menos ainda sobre a qualidade das unidades residenciais produzidas" (Arretche, 1990:27).

Como resultado, o setor privado tem ampla liberdade na provisão do mercado habitacional, o que gera críticas de duas naturezas. A primeira delas refere-se ao projeto de casa própria idealizado pelo governo: este não atende às necessidades dos seus usuários, devido tanto ao espaço físico quanto o número de moradores por unidade. Este problema foi primeiramente apresentado no pós-BNH e se faz presente ainda hoje com o programa MCMV (Cardoso, s/d; Vitruvius, 2012).

O segundo grupo de críticas prende-se com o espaço urbano das cidades. A moradia se refere à unidade física domiciliar (em outras palavras, a unidade habitacional) e o acesso à terra - mais especificamente a terra urbanizada - necessária para a construção, ambos aspetos nocivos às condições de igualdade entre os indivíduos de uma sociedade. Tendo em vista que as unidades habitacionais produzidas pelo poder público atendem a uma faixa de renda com menor poder aquisitivo, baratear o custo total da moradia significa prover unidades habitacionais com espaço físico reduzido e distante dos centros urbanos devido ao valor mais baixo do terreno.

Este problema persiste com o programa MCMV, em que há uma falta de atenção do poder público para este fato, uma vez que são as construtoras que indicam o terreno que será construído as unidades habitacionais (Vitruvius, 2012). As soluções para combater este problema estão previstos na nova Política Habitacional de Habitação, motivo pelo qual as críticas ao MCMV são rígidas, pois representam desarticulação a um objetivo mais abrangente de política pública pensada para a cidade. $O$ que se observa atualmente é a segregação territorial e social dos indivíduos no espaço urbano, pois se aloca as famílias de baixa renda nas áreas periféricas, onde são precários o sistema de transporte e a estrutura urbana como um todo (tal como a existência de rede de iluminação, e coleta de esgoto e água) (Maricato, 1987; 2011).

56 Em terceiro lugar, vale ressaltar o processo de produção das unidades habitacionais. 0 setor privado foi beneficiado pela garantia de investimento contínuo através da fonte de financiamento público - via SBPE (na década de 1960) e historicamente via FGTS colocando-o como o principal agente executor da política habitacional brasileira. Este ator se estruturou numa rede de agentes que controlavam tanto a produção quanto o consumo da unidade habitacional (Maricato, 1987).

57 Enquanto o setor privado provia a casa própria para as famílias de maior poder aquisitivo, cabia ao setor público a provisão às famílias de baixa renda. Mas, durante a gestão do $\mathrm{BNH}$, tanto as construtoras privadas quanto as COHABs não recebiam subsídios para a produção das unidades habitacionais, de forma que os custos eram inteiramente repassados ao beneficiário final (Arretche, 1990). Ambos buscavam financiamento junto ao SBPE e FGTS, respetivamente, e recebiam "subsídios creditícios" para pagamento. Como ambos buscavam a solvência financeira, do ponto de vista dos indivíduos, o tratamento para todas as faixas de renda era praticamente o mesmo, e as agências (tanto público como privadas) operavam segundo uma lógica de mercado: ofertar um produto (a casa própria) para os que podem pagar por ela (Arretche, 1990). 

atendidas por esse molde, devido às altas taxas de inadimplência e baixo retorno no rendimento do financiamento (Arretche, 1990; Maricato, 1987). Logo, ainda que com intervenção estatal, a provisão de uma política de bem-estar social habitacional parece ter sido proposta pelo Estado à população assalariada ou com renda própria (via poupança privada) sem buscar a igualdade no acesso às de baixo poder aquisitivo.

Ao buscar contornar este problema, atualmente o MCMV oferece subsídio financeiro para o beneficiário final. Mas o valor do subsídio (que é quase integral) às famílias de baixa renda é desnecessariamente elevado, e está aplicado via programa que parece desarticulado aos demais instrumentos da Política Nacional de Habitação, lançada em 2004 (Bonduki, 2009; Vitruvius, 2012). Assim, antes que se pense numa ação estatal voltada para a promoção de uma política social aos setores mais necessitados, a política de subsídios parece estar, mais uma vez, beneficiando o setor privado, enquanto fonte de financiamento estável.

Uma das interpretações para a perpetuação dessa linha de ação será a de se tratar de uma real estratégia de política habitacional em que conta mais o crescimento econômico do que uma promoção de bem-estar social (Bonduki, 2009). O incentivo ao setor privado, enquanto agente executor, está intimamente ligado à utilização dessa política social como solução para crises econômicas. A promoção de subsídios via setor público mostra que o Estado está, de fato, intervindo na economia, mas não necessariamente para a promoção do direito à moradia.

\section{Conclusão}

61 Desde a década de 1940, a conceção de atendimento público para a habitação é através da casa própria, pois era histórico o problema dos aluguéis: devido à falta de regulação com a livre atuação do mercado, o alto valor cobrado pelos empreendedores imobiliários não era acessível aos trabalhadores de mais baixa renda (Bonduki, 1994). Esta forma de atendimento também foi escolhida por agregar os interesses econômicos do setor privado; este beneficia da fonte de recurso pública para financiar e comercializar as unidades habitacionais tanto para as famílias de baixa renda quanto para as de maior poder aquisitivo. Como resultado, o setor público beneficia do crescimento econômico produzido pela construção civil.

62 Desde a primeira política nacional de habitação inaugurada durante o Regime Militar (1964-1985), houve uma divisão no atendimento aos cidadãos segundo o poder aquisitivo dos mesmos. Coube ao setor privado atender as famílias de maior renda e ao setor público a incumbência de atender o estrato conhecido como "de interesse social". Esta divisão permanece na nova política habitacional, inaugurada em 2009 com o programa MCMV, que tem sido o de maior destaque entre as ações promovidas pelo Ministério das Cidades.

Em ambos os períodos observados, é possível concluir que a política habitacional brasileira provê um bem privado e não um serviço público, distinto em formato segundo a faixa de renda. Mas o incentivo do setor público na produção de conjuntos habitacionais de interesse social é dominado por uma lógica de mercado: a escolha do terreno e a qualidade da unidade habitacional são mais baratas, o que reproduz uma segregação espacial e social no contexto urbano. 
64 de moradias, denominado "autoempreendimento", pois em ambos é possível localizá-los em áreas distantes do espaço urbanizado, notadamente mal servido de infraestrutura e equipamentos sociais (Bonduki, 2007).

65

Apesar dos avanços no número de unidades habitacionais construídas e do aumento das faixas de renda pelos programas habitacionais de produção, o fomento de outras soluções, tais como programas de urbanização e assentamento de habitações precárias também seria uma alternativa tão eficiente quanto a entrega da unidade habitacional construída. Resta chegar o momento econômico e o cenário político que crie o interesse pelo bemestar do cidadão, e não unicamente dos atores privados envolvidos na habitação.

\section{BIBLIOGRAFIA}

ARRETCHE, Marta (1990), "Intervenção do Estado e Setor Privado: o Modelo Brasileiro de Política Habitacional”, Espaço \& Debates, X (31): 21-36.

BONDUKI, Nabil (1994), Origens da habitação social no Brasil. São Paulo: Estação Liberdade.

BONDUKI, Nabil (2007), “Política Habitacional e Inclusão Social no Brasil: revisão histórica e novas perspetivas no governo Lula", Revista eletrônica de Arquitetura e Urbanismo (nº1), 70-104, [Online] Disponível em: http://www.usjt.br/arq.urb/numero_01/artigo_05_180908.pdf [consultado em: 28 ago, 2012].

BONDUKI, Nabil (2009), "Do projeto moradia ao programa Minha Casa, Minha vida". Teoria e Debate, 82: 8-14, [Online] Disponível em: http://www.teoriaedebate.org.br/materias/nacional/doprojeto-moradia-ao-programa-minha-casa-minha-vida?page=full [consultado em: 12 jun, 2012].

BRASIL (2009), PlanHab: Plano Nacional de Habitação, Brasília, Ministério das Cidades.

CARDOSO, Adauto Lúcio (s/d), "Política Habitacional no Brasil: balanço e perspetivas", Observatório das Metrópoles, [Online] Disponível em: http://

www.observatoriodasmetropoles.ufrj.br/download/adauto_polhab_brasil.pdf [consultado em : 29 ago, 2011].

CARVALHO, José M. (2011), Cidadania no Brasil: o longo caminho, Rio de Janeiro: Civilização Brasileira.

ESPING-ANDERSEN, Gosta (1995), “O futuro do welfare state na nova ordem mundial”. Lua Nova: Revista de Cultura e Política, (35), 73-111. [Online] Disponível em: http://www.scielo.br/pdf/ln/ n35/a04n35.pdf [consultado em: 05 dez. 2012].

FUNDAÇÃO JOÃO PINHEIRO (2009), Déficit Habitacional no Brasil 2007, Contagem: Editora Gráfica Daliana Ltda.

GOMES, Fábio G. (2006), "Conflito social e welfare state: Estado e desenvolvimento social no Brasil”, RAP, 40(2), 201-36. [Online] Disponível em: http://www.scielo.br/pdf/rap/v40n2/ v40n2a03.pdf. [consultado em: 05 dez. 2012].

Configurações, 10 | 2012 
HÖFLING, Eloisa M. (2001), “Estado e políticas (públicas) sociais”. Cadernos CEDES, 21(55), 30-41. [Online] Disponível em: http://www.scielo.br/pdf/ccedes/v21n55/5539.pdf [consultado em: 09 dez. 2012].

KLINTOWITZ, Danielle (2011), “Como as políticas habitacionais se inserem nos contextos de reforma do estado? A experiência recente do Brasil”. Revista Pensamento \& Realidade, XIV, 26 (3): 101-120.

LEFÈVRE, Christian (s.d.), “Governar as metrópoles: questões, desafi os e limitações para a constituição de novos territórios políticos”, Cadernos Metrópoles, 11 (22): 299-317.

MARICATO, Hermínia (1987), Política Habitacional no Regime Militar, Petrópolis: Vozes.

MARICATO, Hermínia (2011), “Metrópoles desgovernadas”, Estudos avançados, 25 (71): 7-22.

MELLO, Marinilzes M. (2007), "Políticas sociais e políticas de bem-estar: algumas considerações”, InterfacEHS, 2(4): 1-20.

RIKER, William (1975), “Federalism”, in F. Greenstein e N. Polsby (orgs.), Handbook of Political Science, vol. 5. Reading, Addison-Wesley Publishing Company: 93-172.

SANTOS, Cláudio H. M. (1999), Políticas Federais de Habitação no Brasil: 1964/1998, Rio de Janeiro: IPEA.

SOUZA, José M. e CARNEIRO, Ricardo (2007), “Moradia popular e política pública na Região Metropolitana de Belo Horizonte: revisitando a questão do déficit habitacional", in Murilo Fahel e Jorge Neves (org.), Gestão e Avaliação de Políticas Sociais no Brasil, Belo Horizonte, Editora PUC Minas: 361-418.

VALENÇA, Márcio M. (1999), “The closure of the Brazilian Housing Bank and Beyond”, Urban Studies, 36(10): 1747-1768.

VALENÇA, Márcio M. (2001), "Habitação no contexto da reestruturação econômica”, Análise Social, XXXVI (158-159): 43-83. Documentos em suporte eletrónico

VITRUVIUS, (2012), [online], disponível em http://www.vitruvius.com.br/revistas/read/ arquitextos/12.133/3936 [consultado em $11 \mathrm{dez} .2012$ ].

\section{NOTAS}

1. Por socioecológicas a autora refere-se às difíceis condições sociais e sanitárias disponíveis aos moradores das periferias.

2. Entre os anos 30 a 60, a produção habitacional era financiada via Institutos de Aposentadoria e Pensão (IAPs), contribuição tripartida entre o empregado, o empregador e o Estado (Bonduki, 1994). Entre os anos 1964 a 1985, a principal fonte de recurso pública era via Fundo de Garantia por Tempo de Serviço (FGTS), contribuição compulsória de $8 \%$ retida na folha de pagamento do empregado (Santos, 1999).

3. Com efeito, a cidade de São Paulo - histórica e contemporaneamente uma das principais cidades do país - aumentou sua população de 23.242, em 1872, para 232.820 em 1900 (Bonduki, 1994).

4. Para mais informações sobre o período habitacional pré-Regime Militar, ver em Bonduki (1994).

5. A década de 1990 consiste em programas habitacionais fomentados pelos governos estaduais municipais, com fraca interferência do Governo Federal. Há interferência dos preceitos 
neoliberais e de reforma do Estado, que podem ser mais bem aprofundados em Klintowitz (2011) e Valença (1999).

\section{RESUMOS}

Argumenta-se sobre a promoção da política de habitação no Brasil durante seus dois períodos de maior investimento financeiro e institucional: o Regime Militar (1964-1985) e o período atual (2003-2012). Em ambos, houve forte intervenção do Estado em várias etapas, enquanto que em outras o papel determinante está no setor privado. Isto ocorre devido ao bem que se provê aos cidadãos: a casa própria. Tal escolha traz aspetos interessantes na análise sobre o papel do Estado na provisão do bem-estar social, a construção da parceria entre o público e privado, e as consequências sociais e econômicas que a casa própria traz para a arquitetura urbana e crescimento econômico no Brasil.

This article argues about the promotion of social housing in Brazil during its two periods of major financial and institutional investments: the Military Regime (1964-1985) and the current period (2003-2012). In both there has been a strong State intervention in several steps, while in others the private setor has had a determinant role. This is due to the good provided to citizens in this area: private housing. Such choice brings interesting aspects in the analysis of the State role in providing welfare, the construction of partnership between the public and private sectors, and the social and economic consequences that it brings to urban architecture and economic growth in Brazil.

L'article fait la discussion sur la promotion du logement social au Brésil pendant les deux périodes de grands investissements financiers et institutionnels : le régime militaire (1964-1985) et la période actuelle (2003-2012).

Dans ces deux cas, il y a eu une forte intervention de l'Etat en plusieurs étapes, tandis que dans d'autres, le secteur privé a joué un rôle déterminant. Cela est dû à la bonne fournie aux citoyens dans ce domaine: le logement privé. Ce choix apporte des aspects intéressants dans l'analyse du rôle de l'État dans la fourniture de l'aide sociale, la construction d'un partenariat entre les secteurs public et privé, ainsi que les conséquences sociales et économiques que la maison propre apporte à l'architecture urbaine et la croissance économique au Brésil.

\section{ÍNDICE}

Palavras-chave: políticas sociais, habitação, setor público, setor privado

Mots-clés: politique sociale, logement, secteur public, secteur privé

Keywords: social policies, housing, public setor, private setor 
AUTOR

WALKIRIA ZAMBRZYCKI DUTRA

Diretora de Fomento à Habitação (2011-2012) da Secretaria de Estado de Desenvolvimento Regional e Política Urbana do Governo do Estado de Minas Gerais (SEDRU-MG)

walkiriazdutra@gmail.com 